\title{
Author Index Vol. 66, 1996
}

Adachi,K. 160 Alexander, R.McN. 137 Asanome, M. 192 Christian, A. 93 Crompton, R.H. 137 Endo,B. 160 Fischer, M. 93 Gilman, S. 204 Günther, M.M. 137 Hase,K. 253 Hayamizu, N. 253

Hirasaki,E. 25,209 Inokuchi, S. 44 Jouffroy, F.K. 55 Kawahara, K. 226 Kimura,T. 5,126,181

Kojima, R. 38 Kumakura, H. 25 Li,Y. 137 Matano, S. 209 Matsumura, A. 44 Matsunami, K. 240 Matsuyama, K. 192

Medina, M.F. 55 Miyamoto,YY. 226 Miyashita,E. 192 Mizuno, N. 240 Mori,S. 192 Morimoto, M. 181 Nakajima,K. 192 Nakano,Y. 25,113 Nakatsukasa, M. 15 Niizeki, K. 226 Nishizawa, S. 160 Ogihara,N. 253 Okada,M. 38,181 Preuschoft, H. 5,68,82,93 Rose,M.D. 5,7 Suzuki, M. 240 Tardieu, Ch. 68, 82 Vilensky, J.A. 204 Wang,W.J. 137 Witte,H. 93 Yamazaki,N. 253 Yamazaki,Y. 240 